\title{
A abordaxe da cronicidade: a encrucillada da Atención Primaria
}

\author{
Addressing chronicity: the crossroads of Primary Care
}

\author{
Ventosa Rial J, Pazo Paniagua MC, Alonso Fachado, A. \\ Medicina Familiar e Comunitaria. EOXI de Santiago de Compostela. Servizo Galego de Saúde.
}

\begin{abstract}
Resumo
0 progresivo envellecemento da poboación galega supón un crecemento nos custos do sistema sanitario e un desafío para a sociedade no seu conxunto para abordar os coidados e necesidades destes pacientes. $\mathrm{Na}$ actualidade a fragmentación do sistema sanitario en niveis e a práctica ausencia dunha coordinación entre estes e os servizos sociais fai necesario o desenvolvemento de instrumentos e canles que optimicen os recursos e melloren de forma progresiva a atención integral das persoas en situación de cronicidade. Durante os últimos anos definíronse diversos modelos de atención á cronicidade nun intento de mellorar a eficiencia da xestión dos sistemas sanitarios. Neste artigo descríbese un modelo de atención integral centrado no traballo en rede e transversal entre os diferentes actores de sistema sanitario implicados na atención á cronicidade, así como as oportunidades de mellora do modelo de atención á cronicidade.
\end{abstract}

\section{Introdución}

Coa publicación no ano 1994 do traballo de Evans, Barer y Marmor titulado Why are some people healthy and others not? ${ }^{1}$ empézase a falar do enfoque poboacional da saúde que inclúe non só os resultados de saúde acadados polas accións realizadas no ámbito sanitario, senón tamén unha serie de factores que actúan como determinantes da saúde, así como as políticas e intervencións necesarias para modificalas.

Este novo concepto supuxo, nos derradeiros anos, un novo enfoque das estratexias de saúde sendo o elemento clave das mesmas, e centrándose nas persoas e non na enfermidade. Desta forma pásase dunha atención reactiva a outra proactiva tanto das necesidades da poboación no seu conxunto como das do individuo en particular.

Con esta nova perspectiva, o modelo asistencial tradicional centrado en patoloxías ou aparatos vese cuestionado, de igual xeito que a división tradicional da asistencia en dous niveis. Dende este punto de vista é necesario desenvolver un enfoque integrador tanto dos niveis asistenciais como daqueles outros actores (servizos sociais, saúde pública, entre outros) implicados no coidado dos diferentes aspectos da saúde. Tamén se fai necesaria unha nova definición das políticas das organizacións sanitarias que impliquen un desenvolvemento de sistemas de traballo que favorezan os aspectos integrais da asistencia (procesos asistenciais integrados)², así como estratexias sanitarias de saúde a medio prazo concretadas en programas cunha visión integral do individuo (non exclusivamente do binomio saúde-enfermidade), unha perspectiva temporal máis ampla e unha participación dos pacientes, cidadáns e asociacións.

A abordaxe das enfermidades crónicas baséase neste enfoque de saúde poboacional que comeza co recoñecemen-

\begin{abstract}
The progressive aging of the Galician population results in increasing costs of healthcare and appears as an emerging social challenge to address the care and needs of older patients. Currently, the fragmentation of the healthcare system and the scarce coordination between healthcare and sociosanitary systems should lead to development of tools and ways to optimize the resources towards integrated chronicity healthcare models. Over the last years, diverse chronicity care models to improve healthcare efficiency, have been defined. This article describes a comprehensive healthcare model focused on networking and cross-working between the different stakeholders involved in chronicity healthcare, as well as the opportunities to implement improvement strategies in chronic diseases management.
\end{abstract}

to dos determinantes de saúde e os procesos conductuais que actúan ao longo de todas as etapas do ciclo vital do individuo, para procurar en cada unha delas a promoción e a prevención da enfermidade cun acceso apropiado aos servizos sanitarios e sociais, e priorizando os grupos máis vulnerables.

0 progresivo envellecemento da poboación, supón un crecemento exponencial das enfermidades crónicas o que implica un incremento nos costos do sistema sanitario e un desafío para a sociedade no seu conxunto de cara a abordar os coidados e as necesidades destes pacientes. Segundo 0 censo poboacional do INE a 1 de xaneiro 2015, o 24,01\% da poboación galega é maior de 64 anos, estando a maior porcentaxe nas provincias de Ourense (30.34\%) e Lugo (28.59\%) e a menor nas da Coruña $(23.35 \%)$ e Pontevedra (21.01\%). Este dato confirma a tendencia que existe da proxección realizada no ano 2010 dun incremento do 6.8\% até chegar ao $28.50 \%$ no ano 2030 de media en Galicia ${ }^{3}$. Os maiores de 64 anos fan un uso máis intensivo da atención sanitaria e son os principais consumidores de produtos farmacéuticos, representando un gasto sanitario per cápita 2,2 veces maior que a media da poboación xeral. A xestión dende o punto de vista sanitario deste envellecemento progresivo é o gran reto do futuro.

$\mathrm{Na}$ actualidade a fragmentación dos sistemas sanitarios en niveis e a práctica ausencia dunha coordinación entre estes e os servizos sociais fai necesario o desenvolvemento de instrumentos e canles que optimicen os recursos e melloren de xeito progresivo a atención integral das persoas en situación de cronicidade. Se ben todos os profesionais dos sistemas socio-sanitarios deben implicarse activamente na mellora da atención á cronicidade, debe existir un axente 
coordinador destes procesos asistenciais relacionados co paciente crónico, sendo esta responsabilidade dos profesionais de medicina e enfermería de Atención Primaria2, 4 . A pregunta é se 0 sistema está preparado para este cambio.

\section{Estratexias fronte a Cronicidade}

Actualmente asistimos a unha eclosión de todos os aspectos relacionados coa cronicidade. Todos os sistemas sanitarios do noso entorno, nacional ou europeo, están a desenvolver estratexias de abordaxe do paciente crónico. Entre as razóns deste auxe das políticas da cronicidade podemos destacar o envellecemento progresivo da poboación, as repercusións sanitarias dos recursos que estas enfermidades necesitan, a perda da calidade de vida e o incremento da discapacidade e a súa elevada morbi-mortalidade. Ademais estes procesos adoitan ter unha progresión lenta e de longa duración que determinan uns custos sanitarios e sociais que poden chegar a comprometer a longo prazo ao propio sistema. Pola contra, moitas destas enfermidades poden evitarse mediante accións proactivas sobre unha serie de factores determinantes de saúde.

As enfermidades crónicas non están definidas dunha maneira estándar pero case todas participan das mesmas características (táboa 1).

As estratexias para a abordaxe dos pacientes crónicos baséanse na demostración de intervencións e experiencias que fan a atención a estes pacientes máis accesible, eficaz e económica, sustentados en modelos integrais ${ }^{5,7}$ que melloran a resposta e a aceptación por parte dos propios pacientes.

Existen unha serie de modelos teóricos da atención á cronicidade que poden servir de base para as futuras estratexias. Os máis importantes son:

\section{0 modelo de estratificación de riscos poboacionais} da Pirámide de Kaiser permanente ${ }^{8}$ (figura 1), este modelo identifica tres niveis de intervención segundo 0 nivel de complexidade do paciente crónico.

A estratificación de riscos naceu nos Estados Unidos impulsada polas aseguradoras privadas. Nelas 0 individuo clasifícase en distintas categorías de acordo á probabilidade de sufrir un deterioro da súa saúde. A aplicación nos sistemas sanitarios permite identificar e xestionar aqueles suxeitos que precisan actuacións máis intensivas (anciáns, pluripatolóxicos, crónicos, etc.) e deste xeito optimizar a asignación de recursos, promover 0 autocuidado, priorizar a intensidade das intervencións e evitar ingresos hospitalarios non programados9.

2. Modelo de Atención a Crónicos, The Chronic Care Model $(C C M)^{6}$. Neste modelo a atención aos crónicos faise dende tres perspectivas que se superpoñen:

a. A Comunidade: as políticas sanitarias e os recursos dispoñibles.

b. Os sistemas de Saúde: organización, deseño da asistencia sanitaria, sistemas de información e apoio á toma de decisións.

c. A interacción entre os pacientes e o sistema sanitario. A finalidade última é contar con doentes activos e informados e equipos de profesionais proactivos con medios e capacidades que permitan ter unha atención de calidade, efectiva e satisfactoria para o paciente.

\section{Modelo de Atención Innovadora ás Condicións Cró-} nicas (AICC), The Innovative Care for Chronic Conditions Framework ${ }^{10}$. Este modelo é unha modificación do CCM proposto pola OMS. Destaca a necesidade dun ambiente político proclive ao desenvolvemento e ás aportacións dos recursos necesarios para a estratexia de crónicos. Insiste no papel da comunidade que aparece incluída como terceiro elemento nas interacción entre os doentes e os equipos sanitarios. Tamén establece a necesidade da integración e coordinación dos servizos sanitarios facendo énfase na prevención e a flexibilidade na toma de decisións baseadas na evidencia científica existente.

Partindo destes modelos teóricos, xorden diferentes experiencias de intervención sobre pacientes crónicos ${ }^{11-13}$ pero a súa implantación nos sistemas sanitarios é moi desigual e limitada debido en parte á complexidade do proceso e á resistencia ao cambio que estes modelos requiren para levarse a cabo.

Táboa 1. Características xerais das enfermidades crónicas

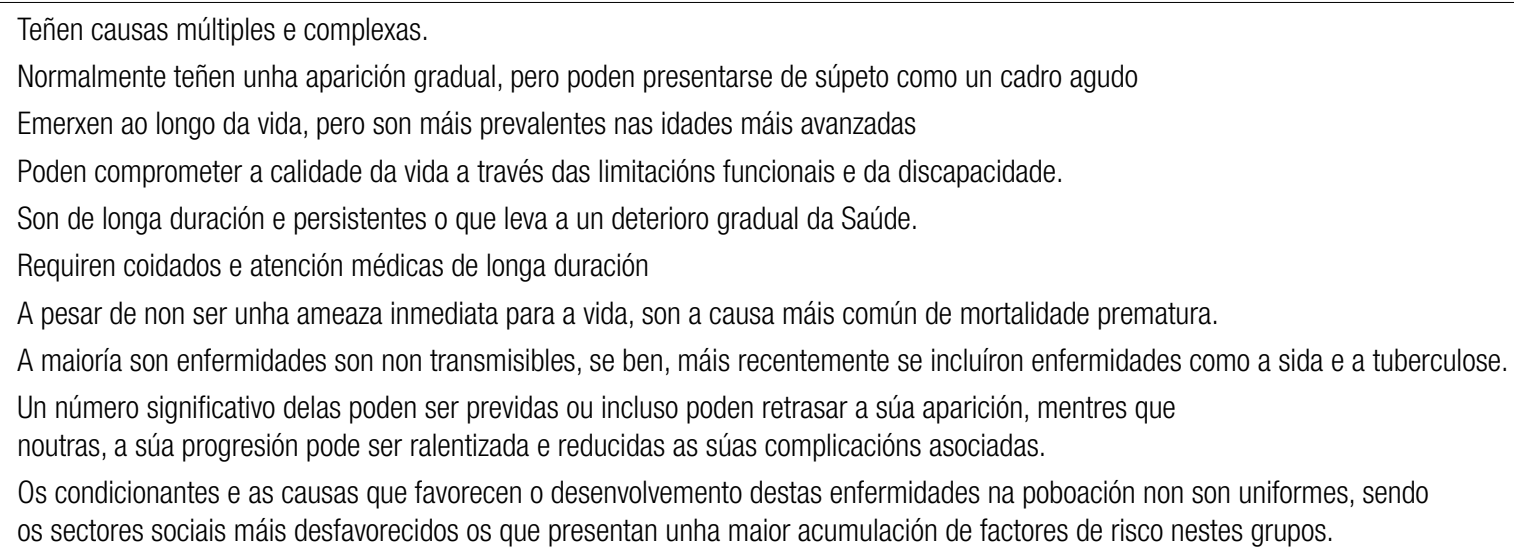

Fonte: Servizos de Estudios e Investigación Sanitaria do Departamento de Sanidade e Consumo do Goberno Vasco. 


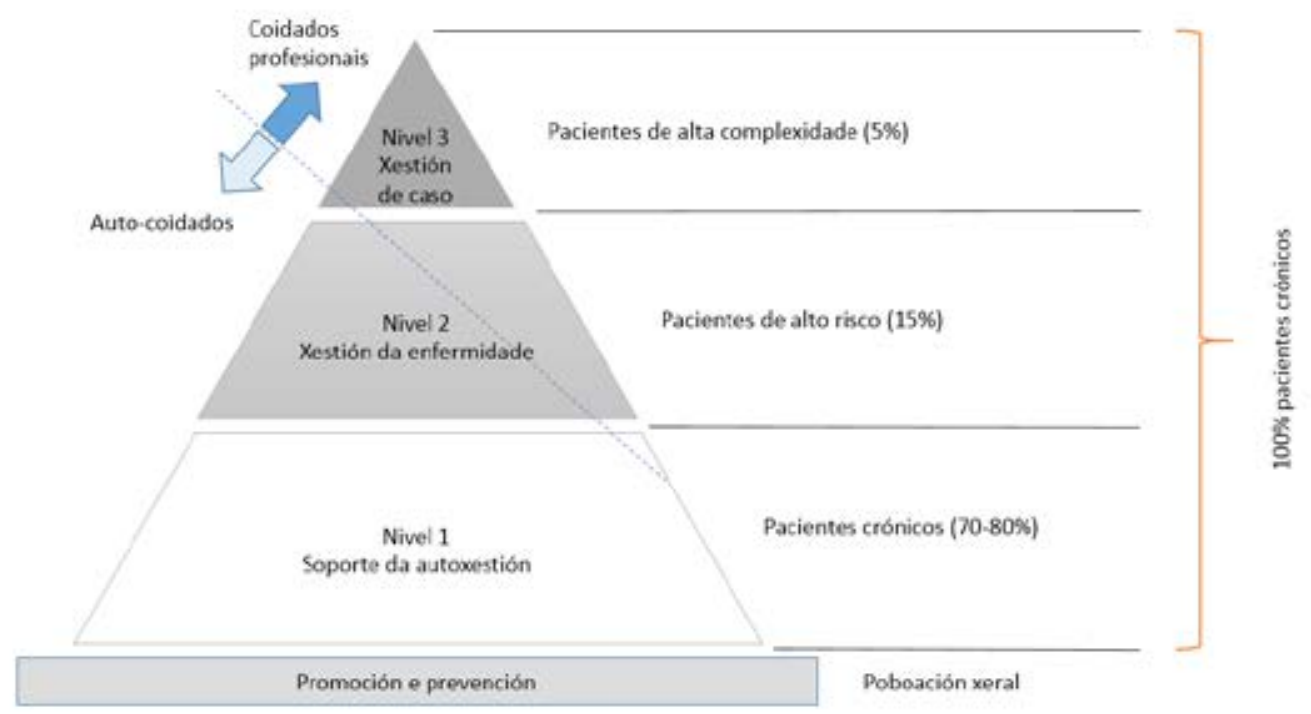

Fonte: Nuî̃o Solis R. Bous prácticas en xestión sanitaria: o caso Kàser Permanente, Estratexia de atención ao paciente crónico en Castela e León. Sacyl.

\section{A Declaración de Sevilla}

No ano 2011 a Sociedade Española de Medicina Interna (SEMI) e a Sociedade Española de Medicina Familiar e Comunitaria (SemFYC), xunto co apoio dos Servizos de Saúde das distintas Comunidades Autónomas (figura 3) e o consenso dun grupo de expertos, elaboraron o Documento de Consenso Atención ao Paciente con Enfermidades Crónicas tamén coñecido como a "Declaración de Sevilla"2.

A finalidade desta declaración é a de promover e estimular iniciativas en todas as comunidades autónomas co fin de desenvolver iniciativas entre as xerencias dos respectivos Servizos de Saúde, as Sociedades Científicas e os pacientes, que revertan nun plan autonómico de atención aos enfermos crónicos en cada Comunidade e aliñada dentro dunha estratexia nacional integrada².

0 deseño dos Plans contemplan unha serie de propostas de intervención que se agrupan en tres áreas:

a. O/a paciente e a comunidade na que se encontra.

b. A organización da atención sanitaria e sociosanitaria e os respectivos sistemas de información clínica.

c. As tomas de decisións clínicas compartidas entre pacientes e profesionais.

Na nosa comunidade é cada día máis evidente o predomino das consultas de patoloxías crónicas sobre as agudas, pero 0 sistema no seu conxunto non foi quen de prever nin de evolucionar ao mesmo ritmo. Nos derradeiros anos, os profesionais sanitarios foron tomando conciencia da necesidade dun novo enfoque que se vén traducindo en iniciativas, de máis ou menos éxito, en atención primaria e hospitalaria (seguimento compartido, hospitais de día ou hospitalización a domicilio, entre outros).
A pesar das diferentes tentativas de mellora estes son feitos illados até a data. Debido á propia magnitude da situación non chega con realizar a implantación destas iniciativas, faise necesario enfrontar un cambio de maior calado. É preciso adaptar e reconfigurar a estrutura asistencial, sen esquecer a atención aos casos agudos, de cara a dar unha resposta integral e complexa, onde se impliquen os diferentes actores sociais. Nun entorno que precisa chegar á beira do paciente no seu propio domicilio.

Ademais a visión global da cronicidade comeza pola promoción saúde e a prevención da propia enfermidade.

É preciso, pois, un cambio nas prioridades tanto políticas como de investimentos para construír un modelo asistencial que faga fronte aos retos que se ven achegar nun futuro inmediato.

A Atención Primaria xa non só é a porta de entrada ao sistema sanitario, neste novo contexto asignáselle 0 papel de coordinador e regulador do fluxo do pacientes no sistema.

Tendo en conta todo o referido xorden dúas cuestións que son a base das reflexións do presente traballo:

1. Pode a Atención Primaria en Galicia asumir na actualidade este novo rol?

2. Está o sistema disposto e deseñado para este novo modelo?

\section{A encrucillada da Atención Primaria} A situación actual

Galicia a principios de 2015 contaba cunha poboación censada de 2.731 .406 habitantes (48,2\% homes e 51,8\% mulleres) distribuída en 315 concellos, unha idade media de 
45,9 anos (nas provincias de Ourense e Lugo esta chega ata os 49 e os 49,5 anos respectivamente), e unha esperanza de vida ao nacer de 82,59 anos. 0 índice de envellecemento en Galicia é de 150,14 e nas provincias de Lugo e Ourense de 215,22 e 226,15 respectivamente ${ }^{14}$.

Segundo os datos do Instituto Galego de Estatística, nos diferentes servizos de Atención Primaria en Galicia traballan 7.392 persoas (táboa 2) que atende a unha poboación de 2.683.781 individuos segundo as fontes de tarxeta sanitaria a 31 de xaneiro de 2015.

Préstase atención en 399 unidades de Atención Primaria e consultorios (agrupados en 142 Servizos de Atención Primaria), 98 Puntos de Atención Continuada (PAC) e 599 Unidades de Apoio (odontoloxía, fisioterapia, matronas, saúde mental, administrativas, etc).

$081.41 \%$ da poboación é atendida por persoal do novo modelo de Atención Primaria que xorde do Decreto 200/1993, do 29 de xullo, de ordenación da Atención Primaria, modificado polo Decreto 161/1996, do 25 de abril, que establece unha nova configuración deste eido asistencial ${ }^{15}$. A media do número de consultas por médico de familia (MF) e día é de 32,42 (21,37 para os pediatras) 0 que resulta nunha media de 8,3 minutos por paciente (14 minutos no casos dos pediatras). A implantación da receita electrónica supuxo un descenso dun 21,1\% no número de citas, pasándose de 40,38 citas efectivas por MF/día en xaneiro do 2010 a 31,8 consultas efectivas MF/día en xullo do 2012.

Táboa 2. Recursos humanos en Atención Primaria, ano 2014. Servizo Galego de Saúde.

\begin{tabular}{|l|r|}
\hline Galicia & 2014 \\
\hline Médico/a & 2589 \\
\hline DUE/ATS & 2131 \\
\hline Auxiliar de enfermería & 245 \\
\hline Celador/a & 396 \\
\hline Administrativo/a & 1060 \\
\hline Asistente social & 77 \\
\hline Farmacéutico/a & 68 \\
\hline Fisioterapeuta & 126 \\
\hline Matrón/a & 148 \\
\hline Odontólogo/a & 100 \\
\hline Pediatra & 329 \\
\hline Técnico/a especialista & 83 \\
\hline Persoal de oficios & 39 \\
\hline Facultativo/a especialista de área (FEA) & 1 \\
\hline TOTAL & 7392 \\
\hline Fonte: Instituto Galego de Estatística & \\
\hline
\end{tabular}

\section{Os compoñentes Atención Primaria}

A estrutura funcional actual da Atención Primaria en Galicia é consecuencia das disposicións do Decreto 200/1993, onde se establece a organización en servizos e unidades de Atención Primaria (SAP e UAP, respectivamente). No mesmo Decreto recóllense as funcións e condicións laborais do persoal que integra estas unidades funcionais. A realidade non pasa de ser un marco teórico carente dunha organización de traballo en equipo sen unha perspectiva integradora da súa actividade ou orientada á consecución duns obxectivos de equipo.

A falta dunha definición precisa e concreta dos obxectivos comúns, das tarefas a realizar e os roles dos compoñentes, xerou unha distribución heteroxénea das cargas de traballo e unha participación desigual dos seus membros nas tarefas conxuntas. Estas razóns xunto coa falta dunha formación para 0 traballo en equipo, as limitacións organizativas e de coordinación ${ }^{16}$, a elevada presión social (medicalización de problemas non médicos) e da propia organización determinada pola crise coa necesidade de acadar aforros na xestión dos recursos sanitarios, constitúen as razóns dun crecente malestar e frustración do persoal estando estas razóns na orixe da chamada crise da Atención Primaria ${ }^{17}$.

Mantendo como piar fundamental a preservación da relación médico-paciente, os equipos e SAP deben reorientar a súa actividade non só á consulta a demanda, senón tamén ao deseño de programas de promoción e prevención da saúde de forma proactiva. Para isto deben deixar de ser un conglomerado de profesionais independentes e constituírse como un equipo de profesionais con obxectivos conxuntos e unha única vontade plasmada nuns acordos orientados ao paciente, á resolución de problemas, á calidade e á seguridade. Esta nova concepción supón a primacía dos intereses do colectivo sobre os individuais, e leva consigo implicacións, lexislativas, contractuais e laborais de difícil definición e implantación.

Se ben a configuración dos SAP sería un punto ambicioso pero de longo recorrido, non debería ser este 0 caso para reclamar un tempo axeitado para a realización de probas e actividades asistenciais, fóra da clásica consulta. Isto supón, como mínimo, consensuar estes tres aspectos organizativos:

1. Organización da actividade e do tempo nas axendas. $A$ desburocratización das consultas, a autonomía dos SAP para organizarse de xeito que a atención a demanda sen cita e a urxente poidan ter resposta en tempo e forma cunha mínima repercusión nas axendas e na consulta programada.

2. Máis flexibilidade na configuración das axendas profesionais mantendo uns adecuados niveis de accesibilidade e calidade.

3. Maior implicación e un maior protagonismo da enfermería. Esta é probablemente unha das reformas máis importantes. A enfermería está chamada a ser a xestora dos pacientes crónicos dentro da atención ${ }^{18}$, isto implica que nela vai a recaer a implementación das actividades de promoción de saúde e prevención dos problemas cró- 
nicos e as complicacións destes pacientes. Debe converterse no primeiro alertante ante os indicios de descompensación e deterioro e debe ser quen coordine coa familia os coidados e a asistencia daqueles pacientes en estadios avanzados e finais da enfermidade.

Velaí dúas necesidades fundamentais:

1. Mellorar a coordinación entre ámbolos dous profesionais (médicos e enfermería) baseada no respecto e reciprocidade.

2. Aumentar a formación e capacitación. Isto só é posible cunha reforma do actual modelo de enfermería. Esta pódese acadar pola creación da especialidade de enfermería de familia ou mediante a instauración dunha carteira de servizos de enfermería de Atención Primaria cunha formación específica en atención comunitaria. Esta derradeira opción pasa por crear unha carteira aberta na que a innovación, as boas prácticas e a implementación de novas técnicas, que puideran ir xurdindo, teñan unha rápida e efectiva incorporación, case de xeito automático, e non ser unha traba para a adaptación da enfermería aos novos tempos.

A enfermería de Atención Primaria debe asumir ese papel principal no seu desenvolvemento profesional. Para iso é necesario un cambio de actitude: do binomio problema/ resposta a unha forma de facer máis ampla, que permita anticiparse, prever os problemas e actuar de forma permanente e non puntual neles.

\section{Atención Hospitalaria}

As crises que vimos arrastrando dende 0 ano 2007, viñeron a cuestionar a sostenibilidade do modelo sanitario no seu conxunto e a poñer sobre a mesa a necesidade de contrastar a eficiencia e o rendemento dos recursos investidos respecto ao impacto en termos de saúde. Esta é a causa de que a excelencia e a sostenibilidade dos hospitais pasen por dar resposta dun xeito adecuado aos retos que condicionan a asistencia neles ${ }^{19}$ :

- Dar resposta a un novo perfil de paciente, cada vez más ancián e pluripatolóxico.

- Posicionarse adecuadamente respecto aos retos que nos presentan as novas tecnoloxías.

- Facer protagonistas aos pacientes das decisións que afecten á súa enfermidade.

- Redeseñar un novo rol entre niveis asistenciais para garantir a continuidade asistencial.

- Acadar vías de provisión de servizos co sector privado sociosanitario.

Limitarémonos neste artigo ao primeiro dos retos que incumbe ao paciente crónico. A estrutura do sistema hospitalario vén desde hai anos dando respostas puntuais, e as máis das veces de xeito case voluntarioso, á crecente demanda destes pacientes, pero coa visión de mitigar a carga, tanto de estadías, como de recursos que supoñen uns pacientes que son reincidentes no uso de seus servizos, chegando a consumir o $70 \%$ dos recursos sanitarios ${ }^{19}$. As respostas dadas ata 0 momento por parte dos hospitais foi, e está sendo, a creación de unidades e dispositivos para a atención ao paciente crónico pluripatolóxico avanzado que dalgún xeito veñen ocupándose a modo de recursos específicos, pero con pouca conexión co outro nivel asistencial.

Estamos nos tempos da transversalidade e o traballo en rede, $\mathrm{e}$ precisamente sobre este concepto debería producirse o cambio cultural, a nova filosofía do enfoque da cronicidade. Sen ter que modificar na súa esencia, a estrutura organizativa dos hospitais deberíase modificar a relación das súas actuacións co paciente crónico. A xestión do paciente crónico nos servizos hospitalarios debe estar regulada e ser única, independentemente da causa ou descompensación que o leve a ingresar nun centro, sendo as actuacións dos diferentes servizos puntuais ou delimitadas no tempo á resolución dun problema concreto. Para acadar este obxectivo fai falta artellar unha organización cunha figura central que sexa o responsable de todos os pasos asistenciais que teña que dar o paciente crónico no ámbito do hospital e ao mesmo tempo a canle de comunicación entre os dous niveis asistenciais. Esta figura, xa descrita como especialista hospitalario interconsultor ${ }^{20,21}$ ou a tan traída enfermería xestora de casos está pendente de desenvolvemento ou ben naqueles procesos onde foi implantada o seu cometido aínda está lonxe do que o marco teórico propón. Sen esquecer estas figuras, deberíase ser máis ambicioso. Se pretendemos dar calado a esta estratexia, deberíase ir máis alá das persoas e reorganizar, total ou parcialmente, os actuais servizos de medicina interna ${ }^{22}$ nos centros hospitalarios (o médico internista, actuando como referente do paciente dentro do hospital), así como os servizos de seguimento de tratamento do paciente crónico, garantindo a transversalidade das actuacións cos outros servizos, agrupando na súa esfera de dependencia todas as unidades e dispositivos que foron creadas con este cometido. 0 servizo de medicina interna sería o derradeiro responsable de garantir a continuidade asistencial, a comunicación e 0 asesoramento coa Atención Primaria ${ }^{23} .0$ encaixe deste modelo, sobre 0 que pivotase a responsabilidade asistencial sería un servizo en vez dun profesional, e tería perfecta cabida no modelo de xestión clínica, onde se podería constituír como tal.

\section{Organización sanitaria}

Coa reorganización da asistencia sanitaria nas novas Xerencias de Xestión Integrada ${ }^{24}$ xurdiron moitas inquedanzas de como iría a repercutir e influír no desenvolvemento da actividade na Atención Primaria. Baséanse na idea de integrar baixo unha soa dirección as decisións de xestión, organización, recursos e persoal co fin de crear estruturas organizativas coa autonomía necesaria para incorporar tanto a xestión clínica como a xestión por procesos mediante a superación dos diferentes niveis asistenciais existentes e a racionalización dos recursos. 0 desenvolvemento e organización dos procesos asistenciais como xeito de traballo, supón definir 0 papel de cada profesional fronte á atención do paciente, así como os procedementos a seguir e os indicadores estándares como garantía da calidade e eficiencia da asistencia. Non se trata, polo tanto, de realizar protocolos para ordenar a derivación de pacientes aos hospitais. 
As dúbidas sobre estas formas de xestión non o son sobre o contido teórico, senón sobre a súa aplicabilidade real e a tendencia a un predominio dos incentivos e indicadores da eficiencia hospitalaria sobre os da eficiencia global do siste$\mathrm{ma}^{25-27}$ (as omnipresentes listas de espera). Os consensos acadados apuntan á necesidade dun cambio cultural na organización, os profesionais teñen que tomar conciencia deste cambio e sentirse integrados non exclusivamente nun nivel asistencial concreto, senón ter o que poderíamos denominar "conciencia de área", sendo parte activa na toma de decisións e liderando o traballo en equipos multidisciplinares.

Tamén son precisos xestores sanitarios que lideren as estratexias de transformación capaces de transmitir e implicar aos profesionais no desenvolvemento destas iniciativas. A profesionalización da xestión mais alá dos avatares políticos podería ser unha garantía de éxito no cambio ${ }^{28,29}$. A avaliación dos resultados a medio prazo será clave para determinar o resultado deste modelo.

0 desenvolvemento e implementación das tecnoloxías da información e da comunicación (TICs), vén a favorecer a aproximación dos profesionais e constitúe unha das pezas fundamentais na que sustentar a integración e os modelos transversais de actuación sobre o paciente crónico. A existencia dunha historia clínica única, os sistemas de telemedicina e as comunicacións informáticas, son ferramentas técnicas que axudan pero son exclusivamente iso, ferramentas, non obxectivos en si mesmas. A responsabilidade da organización sanitaria é facer un bo aproveitamento destes elementos, garantindo a bidireccionalidade do seu uso, na procura de conseguir un modelo onde todos os actores se sintan partícipes e cómodos, e non só meros elementos que se dilúen nuns obxectivos que lles resultan totalmente alleos. Sen renunciar aos obxectivos de carácter persoal, temos que ir a unha crecente priorización dos obxectivos por equipo, só posible se o persoal os sente como propios.

A autonomía na xestión dos servizos sanitarios ${ }^{28}$ pode ser a resposta. Esta ten como finalidade un maior aproveitamento dos recursos, mediante a implicación dos profesionais nun proceso de deseño organizativo que permita a xestión dos recursos utilizados na práctica clínica. Supón, por tanto, facer unha planificación e tomar decisións naqueles aspectos da súa actividade que teñan mostrado unha maior efectividade tendo en conta a evidencia científica dispoñible e a relación custo-beneficio na procura da sostenibilidade do sistema sanitario. E por suposto, tamén nun retorno, en forma de incentivo, dos obxectivos acadados. Este é o modelo das Unidades de Xestión Clínica.

A finalidade non é outra que implicar ao profesional na xestión dos centros, reforzar a continuidade asistencial, mellorar a organización do traballo e a satisfacción dos pacientes. Pero o seu desenvolvemento ten grandes retos ${ }^{30}$. Un deles é como contemporizar o sistema organizativo e xerárquico actual dos centros con este novo modelo de xestión, especificar ata onde chega a autonomía de xestión (recursos humanos, económicos, materiais...) e como vencer as resistencias que tanto dende ámbitos profesionais como de relacións laborais se van a atopar.

\section{A Poboación}

Non debemos esquecer os cambios sociais das últimas décadas, a evolución nos hábitos de vida (sedentarismo, tabaquismo), 0 incremento da idade da poboación e o descubrimento de novos tratamentos que teñen convertido en crónicas enfermidades que antes tiñan unha alta taxa de mortalidade (sida, cancro, etc. . .). Todo isto supón un incremento no número de pacientes con enfermidade crónica avanzada. Tampouco podemos esquecer o cambio de tipoloxía do paciente e do seu entorno, con máis acceso á información, máis nivel cultural e máis demandantes de coidados de calidade e técnicamente mais avanzados ${ }^{31}$. Estes determinantes supoñen unha carga máis a un sistema que foi deseñado no seu día para dar resposta a procesos agudos e unha presión crecente sobre o gasto sanitario nuns tempos de crise económica. Imponse a necesidade de racionalizar os recursos e reflexionar sobre prioridades de cara a garantir a sostenibilidade do sistema cos máximos de calidade e eficacia. Esta reflexión non só compete aos profesionais e á administración sanitaria, senón que debe involucrar aos usuarios tanto no referente aos autocoidados e á promoción da súa saúde como no uso con xuízo e responsabilidade dos recursos sanitarios.

Débese cambiar o rol tradicional do paciente receptor pasivo dos coidados que ofrece 0 sistema, polo dun paciente activo que sexa cada vez máis responsable e máis consciente do que pode facer para manter e mellorar a súa propia saúde. Esta é unha tarefa non exenta de problemas, no ámbito dun entorno social, afeito a demandar solucións sen máis contrapartida.

0 desenvolvemento participativo do paciente na súa saúde, implica un novo xeito de relación cos distintos profesionais implicados no seu coidado e seguimento, e que as máis das veces incumbe tamén ó seu entorno e coidadores. A tal fin é preciso a implantación de iniciativas que teñan como finalidade que tanto o paciente como as persoas coidadoras teñan os coñecementos necesarios da súa enfermidade (paciente experto) ${ }^{32}$ de acordo ao seu nivel de comprensión, motivalos para a súa implicación no seu seguimento e dotalos das ferramentas necesarias para que poidan adoptar as decisións que en cada momento sexan as máis favorables para o paciente. Estas actividades deberían ser complementarias e supervisadas polos profesionais responsables. Neste cambio é necesario contar con alianzas. A creación de espazos onde as asociacións de pacientes e familiares, xunto cos profesionais implicados poidan intercambiar información, realizar talleres de formación e capacitación nos autocoidados, así como promover intervencións e programas está dirixida a ese fin ${ }^{33,34}$. Tamén é necesario establecer novas canles de comunicación entre os pacientes/coidadores tanto cos profesionais como co sistema sanitario en xeral, que garantan 0 asesoramento e 0 acompañamento non presencial, ou que permitan dilucidar dúbidas e mellorar a accesibilidade.

\section{Conclusións}

0 futuro da sanidade non pasa pola creación de novos servizos, senón pola procura de solucións transversais que pivoten 
sobre Atención Primaria, cun papel relevante da enfermería e da que formen parte tamén os especialistas hospitalarios ${ }^{35}$. Neste futuro a Atención Primaria ten moito que facer. 0 feito de que o cidadán cunha enfermidade crónica teña ao primeiro nivel asistencial como referente para todos os aspectos da súa saúde vai favorecer un cambio na súa percepción. 0 paciente vai mellorar a súa capacidade resolutiva, a súa relación co nivel asistencial hospitalario, tanto na continuidade como na complicidade na continuación dos seus coidados tendo a enfermería como referente inmediato, comunicador e formador da súa area de influencia.

Pola súa parte as organizacións hospitalarias teñen que reorientar a súa organización e os seus recursos para dar unha resposta aos procesos crónicos complexos e pluripatolóxi$\cos ^{36}$. Esa resposta ten que ser global e non quedar restrinxida unicamente a diminuír a sobrecarga para os centros hospitalarios destes pacientes, garantindo os medios necesarios para 0 control e seguimento no medio ambulatorio, revalorizando 0 valor da continuidade de coidados, a prevención e a formación tanto dos profesionais como da cidadanía.

A innovación na atención de saúde nas enfermidades crónicas, en contra do que se ten dito, non consiste tanto na introdución de novas ideas, métodos ou programas para trocar o modo de previr e xestionar estas enfermidades, senón de aproveitar ben os recursos existentes, de implicar a todos (organización, persoal sanitario, pacientes e coidadores) na súa organización e prestación e sobre todo, ter un mínimo sentido común. Neste punto é necesario concretar o quen, 0 como e o con que. E aquí veñen os retos, a necesidade dos cambios e as dúbidas e temores en levalos adiante.

\section{Bibliografía}

1. Evans R, Barer M, Marmor T. ¿Why are some people healthy and others not? The Determinants of Health of Populations. New York, NY: Aldine de Gruyter; 1994.

2. Ollero Baturone $M$, Orozco Beltrán $D$, Domingo Rico $C$, Román Sánchez $P$, López Soto $A$, Melguizo Jiménez M, Bailón Muñoz E, Ruiz Cantero A, Ortiz Camúñez MA, Cuello Contreras JA. "Declaración de Sevilla" conferencia nacional para la atención al paciente con enfermedades crónicas. Rev Clin Esp. 2011; 211: 604-6

3. Fernández Fernández M, Meixide Vecino A. Declive demográfico en galicia y territorio: el diseño de políticas públicas en un espacio complejo y heterogéneo". Santiago de Compostela: Escola Galega de Administración Pública, 2013. ISBN: 978-84-453-5067-6.

4. Consejería de Salud. Junta de Andalucía. Plan Andaluz de Atención Integrada a Pacientes con enfermedades Crónicas 2012/2016. D.L.: SE 1291-2012. Dispoñible en: http://www. juntadeandalucia.es/salud/export/sites/csalud/galerias/documentos/p_2_p_2_planes_ integrales/PIEC.pdf

5. Wagner EH, Austin BT, Von Korff M. Organizing care for patients with chronic illness. Milbank Q. 1996;74(4):511-44.

6. Edward H. Wagner, MD, MPH, Director, MacColl Institute for Healthcare Innovation, Center for Health Studies, Group Health Chronic Disease Management: What Will It Take To Improve Care for Chronic IIIness? Effective Clinical Practice.1998;1:2-4

7. Solberg LI, Asche SE, Shortell SM, Gillies RR,Taylor N, Pawlson LG, Scholle SH, Young. MR.Is integration in large medical groupsassociated with quality? Am J Manag Care. 2009 Jun 1;15(6):e34-41

8. Nuño R. Buenas prácticas en gestión sanitaria: el caso Kaiser Permanente. Rev Adm Sanit. 2007; 5(2): 283-292.

9. Bengoa $R^{\star}$, Martos $F^{*}$, Nuño $R^{\star}$, Kreindler $S$, Novak T, Pinilla R. [ ${ }^{*}$ Contribuyentes principales] Management models. En: Jadad AR, Cabrera A, Martos F, Smith R, Lyons RF. When people live with multiple chronic diseases: a collaborative approach to an emerging global challenge. Granada: Escuela Andaluza de Salud Pública; 2010. Dispoñible en: http://www. opimec.org/equipos/when-people-live-with-multiple-chronic-diseases.

10. Observatory of Innovative Practices for Complex Chronic Diseases Management. [Website].Taxonomy. Available at: http://www.opimec.org/glosario

11. Bernabeu-Wittel M, M. Ollero-Baturone M, Moreno-Gaviño L, et al. Development of a new predictive model for polypathological patients. The PROFUND index. Eur J Intern Med 2011 Jun; 22(3):311-7. doi: 10.1016/j.ejim.2010.11.012
12. Clark CM Jr, Snyder JW, Meek RL, Stutz LM, Parkin CG. A systematic approach to risk stratification and intervention within a managed care environment improves diabetes outcomes and patient satisfaction. Diabetes Care. 2001; 24(6):1079-86.

13. Gérvas J, Pérez Fernández M. Modelo de Atención a Crónicos (Chronic Care Model) y otras iniciativas de mejora de la calidad de la atención a los pacientes crónicos. AMF. 2009;5:35664

14. Instituto Galego de Estatística (IGE) Dispoñible en : http://www.ige.eu/web/index.jsp?paxina $=001 \&$ idioma $=\mathrm{gl}$

15. Secretaría Xeral Técnica. Consellería de Sanidade. Sistema Público de Saúde de Galicia Memoria 2009, pag 119. DL: PO 789-2008. Dispoñible en: https://ibraria.xunta.gal/es/ sistema-publico-de-saude-de-galicia-memoria-2009

16. Fundación $1^{\circ}$ de mayo. Expectativas y realidades en la Atención Primaria española. Ediciones GPS. Madrid. Depósito Legal: M-11080-2010. ISBN: 978-84-9721-411-7. Dispoñible en: http://www.nod050.org/fadsp/pdf/ATT\%20PRIMARIA.pdf

17. La Atención Primaria del futuro Federación de Asociaciones para la Defensa de la Sanidad Pública. Dispoñible en: www.fadsp.org

18. Grupo de crónicos de FAECAP. Las enfermeras comunitarias ante las necesidades de las personas en el siglo XXI. Estrategia ante las personas con problemas crónicos. Estrategia ante la dependencia y la fragilidad. Mayo 2012.

19. Carretero Alcántara L. Pensando el hospital del futuro En: Sociedad Española de Directivos de Atención Primaria. Un nuevo hospital para una nueva realidad. Madrid: Editorial Saned; 2011. p: 85-95. Dispoñible en: http://www.sedap.es/documentos/Informe_SEDAP_2011. pdf

20. Sociedad Española de Directivos de Atención Primaria. Estrategia de gestión de crónicos. Documento de Consenso. Madrid: Spanish Publishers Associates; 2013. Dispoñible en: http://static.correofarmaceutico.com/docs/2013/03/06/cronico.pdf

21. Dirección General de Asistencia Sanitaria. Dirección Regional de Desarrollo e Innovación en Cuidados. Consejería de Salud. Junta de Andalucía. Manual de la gestión de casos en Andalucía. Enfermeras gestoras de casos en el hospital. Febrero, 2007. Dispoñible en: http://www.index-f.com/lascasas/documentos/lc0245.pdf

22. Ollero Baturone M. Modelos de organización para la atención de pacientes crónicos complejos. En: Libro de ponencias: Foro de gestión clínica 2.0. Nuevas prespectivas para una nueva década. Escuela Andaluza de Salud Pública, Granada. 2009. Dispoñible en: http:// si.easp.es/gestionclinica/wp-content/uploads/2009/10/Doc-2.-Modelos-de-organizacion-para-la-atencion-a-pacientes-cronicos-complejos-_Ollero-Baturone-M._pdf

23. Ollero Baturone M. Médicos de familia e internistas trabajando por una atención integral. Sevilla: Editorial Minerva Documento SEMI-semFYC 1998;p. 42-3.

24. Decreto 168/2010, de 7 de octubre, por el que se regula la estructura organizativa de gestión integrada del Servicio Gallego de Salud. Dispoñible en: http://www.xunta.es/dog/ Publicados/2010/20101015/Anuncio30752_es.html

25. Tamborero Cao G. Integración entre atención primaria y atención hospitalaria, ¿La panacea de la coordinación entre niveles asistenciales? En: Economía y salud: boletín informativo. ISSN 1133-6536, №. 74, 2012, págs. 8-10

26. Gené J, Contel JC, Jodar G. Yes, we can. Aten Primaria. 2009;41:181-3.

27. Pou-Bordoy J, Gené-Badia J, de la Cámara-González $C$ et al. Gerencia única: una ilusión sin evidencia. Aten Primaria. 2006;37:231-4. doi: 10.1157/13085954. Dispoñible en: http://www.elsevier.es/es-revista-atencion-primaria-27-articulo-gerencia-unica-una-ilusion-sin-13085954

28. Peiró M, Barrubés J. Nuevo contexto y viejos retos en el sistema sanitario. Rev Esp Cardiol. 2012;65:651-5- Vol. 65 (7). D0l: 10.1016/j.recesp.2012.02.019. Dispoñible en: http:// www.revespcardiol.org/es/nuevo-contexto-viejos-retos-el/articulo/90141413/

29. Sociedad Española de Directivos de Atención Primaria. Integración Asistencial: ¿Cuestión de Modelos? Claves para un Debate. Informe de la Sociedad Española de Directivos de Atención Primaria (SEDAP). Madrid: Saned; 2010. ISBN: 978-84-96835-44-3. DL: M-44246-2010. Dispoñible en: http://www.sedap.es/documentos/Informe_SEDAP_2010.pdf

30. Gutierrez Morlote J. Gestión clínica y sentido común. Rev Esp Cardiol. 2002; Vol. 55(12): $1226-9$

31. AT Kerney. La sostenibilidad del Sistema Nacional de Salud: ¿Ha dejado la sanidad de ser una prioridad social? Informe. Madrid, 2011. Dispoñible en: http://www.farmaindustria.es/ idc/groups/public/documents/notaprensa/farma_110701.pdf

32. González Mestre A, Fabrellas Padrés N, Agramunt Perelló M et al. De paciente pasivo a paciente activo. Programa Paciente Experto del Institut Català de la Salut. Revista de innovación sanitaria y atención integrada. Vol. 1 (1), Artigo 3. 2008. Dispoñible en: http:// pub.bsalut.net/cgi/viewcontent.cgi?article=1001\&context=risai

33. Gerencia Regional de Salud de Castilla y León. Consejería de Sanidad. Junta de Castilla y León. Estrategia de Atención al paciente crónico en Castilla y León. 2011. Disponible en: http://www.saludcastillayleon.es/institucion/es/planes-estrategias/estrategia-atencion-paciente-cronico-castilla-leon

34. Xunta de Galicia. Escola Galega de Saúde para Cidadáns. Dispoñible en: http://www.sergas.es/docs/EGSPC/EscolaGalSauCid.pdf

35. Mosquera Álvarez R, Lado Lema E, Monteagudo Romero J. Del hospital al sistema sanitario del futuro. En: Sociedad Española de Directivos de Atención Primaria. Un nuevo hospital para una nueva realidad. Madrid: Saned, 2011 p: 122-127. ISBN: 978-84-96835-55-9. Dispoñible en: http://www.sedap.es/documentos/Informe_SEDAP_2011.pdf

36. Montes Santiago J, Casariego Vales E, de Toro Santos M, Mosquera E. La asistencia a pacientes crónicos y pluripatológicos. Magnitud e iniciativas para su manejo: La Declaración de Sevilla. Situación y propuestas en Galicia. Galicia Clin 2012; 73 (Supl.1): S7-S14. 